\title{
Very Long-term Survival and Late Sudden Cardiac Death in Cardiac Resynchronisation Therapy Patients
}

Authors: Sergio Barra $\mathrm{MD}^{1} *$, Rudolf Duehmke $\mathrm{MD} \mathrm{PhD}^{2} *$, Rui Providencia MD PhD 3 , Kumar Narayanan $\mathrm{MD}^{4,5}$, Christian Reitan $\mathrm{MD}^{6}$, Tomas Roubicek MD $\mathrm{PhD}^{7}$, Rostislav Polasek $\mathrm{MD}^{7}$, Antony Chow $\mathrm{MD}^{3}$, Pascal Defaye $\mathrm{MD}^{8}$, Laurent Fauchier $\mathrm{MD} \mathrm{PhD}^{9}$, Olivier Piot $\mathrm{MD}^{10}$, Jean-Claude Deharo $\mathrm{MD}^{11}$, Nicolas Sadoul MD PhD ${ }^{12}$, Didier Klug MD PhD ${ }^{13}$, Rodrigue Garcia $\mathrm{MD}^{14}$, Seth Dockrill $\mathrm{MD}^{15}$, Munmohan Virdee $\mathrm{MD}^{15}$, Stephen Pettit MD $\mathrm{PhD}^{15}$, Sharad Agarwal $\mathrm{MD}^{15}$, Rasmus Borgquist $\mathrm{MD} \mathrm{PhD}^{6}$, Eloi Marijon $\mathrm{MD} \mathrm{PhD}^{5,16,17}$ and Serge Boveda MD $\mathrm{PhD}^{18}$, On Behalf of the French-British-Swedish-Czech CRT Network

* The first two authors contributed equally to the paper

${ }^{1}$ Cardiology Department, Hospital da Luz Arrabida, V. N. Gaia, Portugal

${ }^{2}$ Cardiology Department, West Suffolk Hospital, West Suffolk, UK

${ }^{3}$ Barts Heart Centre, Barts Health NHS Trust, London, UK

${ }^{4}$ Cardiology Department, MaxCure Hospitals, Hyderabad, India

${ }^{5}$ Paris Cardiovascular Research Center (Inserm U970), Cardiovascular Epidemiology Unit, Paris, France

${ }^{6}$ Arrhythmia Clinic, Lund University, Skane University Hospital, Lund, Sweden

${ }^{7}$ Department of Cardiology, Regional Hospital Liberec, Liberec, Czech Republic

${ }^{8}$ Arrhythmia Department, University Hospital, Grenoble, France

${ }^{9}$ Service de Cardiologie, Centre Hospitalier Universitaire Trousseau; Faculté de Médecine, Université François Rabelais, Tours, France

${ }^{10}$ Centre Cardiologique du Nord, Saint Denis, France

${ }^{11}$ Cardiology Division, Hôpital La Timone, Marseille, France

${ }^{12}$ Cardiology Division, Nancy University Hospital, Nancy, France

${ }^{13}$ Cardiology Division, Lille University Hospital and University of Lille, Lille, France

${ }^{14}$ Cardiology Division, Poitiers University Hospital, Poitiers, France

${ }^{15}$ Department of Cardiology, Papworth Hospital NHS Foundation Trust, Cambridge, UK

${ }^{16}$ Cardiology Department, European Georges Pompidou Hospital, Paris, France

${ }^{17}$ Paris Descartes University, Paris, France

${ }^{18}$ Cardiology Department, Clinique Pasteur, Toulouse, France 


\section{Corresponding author:}

Serge Boveda, MD PhD

Cardiology Department, Clinique Pasteur, Toulouse, France

E-mail address: sboveda@clinique-pasteur.com

Word count: 4994 


\begin{abstract}
Introduction: The very long-term outcome of patients who survive the first few years after receiving cardiac resynchronization therapy (CRT) has not been well described thus far. We aimed to provide long term outcomes, especially with regard to the occurrence of sudden cardiac death (SCD), in CRT patients without (CRT-P) and with defibrillator (CRT-D).
\end{abstract} Methods: A total of 1775 patients, with ischaemic or non-ischaemic dilated cardiomyopathy, who were alive 5 years after CRT implantation, were enrolled in this multicentre European observational cohort study. Overall long-term mortality rates and specific causes of death were assessed, with a focus on late SCD.

Results: Over a mean follow-up of 30 months [interquartile range 10-42 months] beyond the first 5 years, we observed 473 deaths, giving an unadjusted mortality rate of 139 and 94.7 per 1000 patient-year in CRT-P and CRT-D patients, respectively. The adjusted hazard ratio (HR) for all-cause mortality was 0.99 (95\% CI 0.79-1.22). Twenty-nine patients in total died of late SCD (14 with CRT-P, 15 with CRT-D), corresponding to $6.1 \%$ of all causes of death in both device groups. Specific annual SCD rates were 8.5 and 5.8 per 1000 patient-years in CRT-P and CRT-D patients, respectively, with no significant difference between groups (adjusted HR 1.0, 95\% CI 0.45-2.44). Death due to progressive heart failure represented the principal cause of death (42.8\% in CRT-P patients and 52.6\% among CRT-D recipients), whereas approximately one third of deaths in both device groups were due to noncardiovascular death.

Conclusions: In this first description of very long-term outcomes among CRT recipients, progressive heart failure death still represented the most frequent cause of death in patients surviving the first five years after CRT implant. By contrast, SCD represents a very low proportion of late mortality irrespective of the presence of a defibrillator. 


\section{INTRODUCTION}

Cardiac resynchronization therapy (CRT) devices have revolutionized the treatment of heart failure patients with severe left ventricular (LV) systolic dysfunction and prolonged QRS duration. Randomized data have shown that CRT can decrease mortality through a reduction in both heart failure and sudden cardiac death (SCD) (1). These benefits are seen soon after implantation but appear to persist during longer follow-up (2). Responders, especially superresponders to CRT, are at relatively lower risk of long-term cardiac mortality (3). Whether the primary prevention implantable cardioverter-defibrillator (ICD) improves outcomes over and above CRT is a matter of ongoing debate (4-7), with the recent CeRtiTuDe cohort study revealing that the majority of the excess mortality among CRT-Pacemaker (CRT-P) subjects at 2-year follow-up is related to an increase in non-SCD (8).

Although a progressively diminishing risk of SCD among heart failure patients in general has been recently reported (9), there are no data specifically on very late causes of death among patients who have survived the initial period following CRT implantation. It is plausible that these patients may represent a lower risk group not only for death in general but specifically SCD. The continued analysis of the MADIT-CRT study, which enrolled patients in NYHA class I-II, showed that CRT was associated with continuing benefit over long-term follow-up in patients with mild heart failure and left bundle branch block (10), but whether this benefit extends to real-life patients with more advanced heart failure is unclear.

In this context, a better comprehension of the relative contribution of late SCD as opposed to other competing causes of late mortality in the CRT population, similar to what has been previously assessed in the CeRtiTuDe cohort study for a shorter duration of followup, may provide valuable insight on the relative usefulness of CRT-D and CRT-P in this

population. In this large European multicentre study, we assessed the very-long term outcome 
and late causes of death among CRT patients who survived the first 5-years postimplantation, with a particular focus on late SCD.

\section{METHODS}

\section{Study design and setting}

Data obtained from a large European CRT consortium comprising French, UK, Czech and Swedish patients who received CRT implantation/upgrade between 2002 and 2012 in the context of ischaemic or non-ischaemic dilated cardiomyopathy, and who completed at least 5 years of follow-up(8,11-15). The indications for CRT, with or without a defibrillator, were as per the European Society of Cardiology and European Heart Rhythm Association guidelines(16) for those treated in French, Czech and Swedish Hospitals and the National Institute for Health and Care Excellence (NICE) guidelines [https://www.nice.org.uk/guidance/ta120] for British patients. We assessed the very longterm outcome of these patients and their causes of death in an intention-to-treat fashion, with a focus on late SCD. The 5-year cutoff was chosen for two reasons: firstly, it represents the median CRT-D battery-life(17) - the longevity of CRT-D devices is still sub-optimal and significantly overestimated by industry-published product performance reports(18), with almost half of implanted devices requiring replacement due to battery depletion within 5 years(17); secondly, including only patients having elective CRT generator replacement (rather than a pre-specified cutoff) would result in a wide range of follow-up durations within the study population, considering the much longer battery life of CRT-P compared with CRT$\mathrm{D}$, and therefore comprise patients at varying stages of their post-CRT clinical course and with varying degrees of cumulative CRT exposure. Essentially, the pre-specified cutoff was used to reduce heterogeneity in the study population. 
This study complies with the Declaration of Helsinki. The data collection and analysis were approved by the individual sites' institutional review board or ethics committee.

\section{Sample characterization}

Of 5,782 consecutive patients with ischaemic or non-ischaemic DCM who received CRT implantation or upgrade between January 2002 and February 2013, 1775 completed at least 5 years of follow-up (1241 with CRT-D [69.9\%] and 534 with CRT-P [30.1\%]). Data collected: age, sex, aetiology of cardiomyopathy (ischaemic vs. non-ischaemic DCM), glomerular filtration rate estimated by The Modification of Diet in Renal Disease (MDRD) Study equation, history of atrial fibrillation, chronic obstructive pulmonary disease, cerebrovascular event, diabetes mellitus, cancer, type of device (CRT-D or CRT-P), de novo implantation vs. upgrade, indication for the ICD (primary vs. secondary prevention), LV ejection fraction, medications including beta-blocker, angiotensin-converting enzyme inhibitor (ACEi) or angiotensin II receptor blocker (ARB-II) and aldosterone antagonist, clinical CRT response (positive response defined as improvement in NYHA class) and a history of ICD therapy.

\section{Study Endpoints and Follow-up}

The primary endpoints of this study were all-cause mortality and late SCD. Late SCD was defined as an unexpected sudden death occurring due to cardiac causes within one hour from the start or acute deterioration of any cardiac-related symptoms, or that which occurred within 24 hours of the patient last being seen alive and stable, with no other plausible (noncardiac) cause for a sudden death found during autopsy or reported in the death certificates.

The methods used for collecting cause-of-death data have been described elsewhere $(7,12,14)$. In the DAI-PP registry(12), vital status data were obtained from the 
hospital or general practitioner and systematically controlled through the National Institute of Statistics Economical Studies, whereas causes of death were obtained by the investigators and/or by the French Center on Medical Causes of Death and adjudicated after consideration of all the available information including medical data obtained by the regional investigators, pathology reports and Emergency Medical Services reports. Cause-of-death data for UK and Czech patients were collected by the investigators through analysis of death certificates and necropsy results, clinical notes from hospital admissions and information provided by the patients' General Practitioners, with an agreement between at least two different investigators required for allocating deaths into a specific cause. Data for Swedish patients were gathered from the Swedish National Patient registry and the Swedish pacemaker registry and crosschecked with manual assessment of electronic medical records, while causes of death were retrieved from the Swedish Cause of Death Register. Deaths were categorised into four major groups: SCD, previously defined; progressive heart failure death, defined as death due to progressive circulatory failure over a period of weeks or months without any precipitating acute event; other cardiovascular death, defined as any mortality due to a cardiovascular cause which did not fulfil the criteria for SCD or heart failure death; noncardiovascular death. When insufficient information was available to make a reasonable assumption of the cause of death, the death was classified as unidentifiable.

Follow-up visits were performed in general every 6 months, although additional visits or remote ICD interrogations were also performed in CRT-D patients receiving ICD shocks.

\section{Statistical Analysis}

Statistical analysis was performed using IBM SPSS Statistics, v.24. Baseline characteristics were described with mean \pm standard deviation for continuous data and counts and proportions for categorical data. The Kolmogorov-Smirnov test was used to test the normal distribution of 
continuous variables. The Chi-square test, Student's t-test and non-parametric equivalent tests were used when appropriate. $\mathrm{P}$ values $<0.05$ (two-sided) were considered statistically significant. Missing data, assumed to be random, were treated with multiple imputation by chained equations.

We compared the mortality rates of the study population with that of the original cohort from which our patients were retrieved to test the hypothesis that patients who survive at least 5 years of follow-up represent a lower risk group for death in general. Having completed 5 years of follow-up, the study group is on average 5 years older than the original population of patients implanted with CRT. As such, we used the 1976 European Standard Population as reference for calculating annual age-standardized mortality rates(19). Briefly, mortality and population data in our study group and the original CRT cohort were organized into five-year age groups, up to $85+$ years, to correspond with the age categories used in the European Standard Population. Age-specific crude rates were calculated, and we then estimated age-standardized rates per 1000 patient-years with $95 \%$ confidence intervals using the direct method, based on the age-specific crude rates in each population and the agestructure of the European Standard Population. Finally, the number of deaths per 1000 patient-years were divided by the mean number of years of follow-up in each group to obtain the annual age-standardized mortality rates.

Predictors of late all-cause mortality and late SCD were sought using multivariate analysis with adjustment on the conditional probability of receiving CRT-D rather than CRT$\mathrm{P}$ (the propensity score, PS, estimated with logistic regression). For obtaining the propensity score, we included all baseline covariates that were shown to affect the outcome in our patients (in univariate analysis)(20). The following parameters were included: Age, NYHA class, renal function, upgrade vs. de novo implantation, etiology (ischaemic vs. dilated nonischaemic), history of atrial fibrillation, cancer, stroke, COPD or diabetes, LV ejection 
fraction, use of beta-blockers and site (country) of implantation. All variables were collected at baseline. Further variables which did not help outcome prediction were not included in the model. Proportional hazards regression was used for identifying predictors of all-cause mortality, while the analysis on late SCD was performed using the Fine-Gray model for obtaining subdistribution hazard ratios (sHR), thereby taking the competing risk of non-SCD into consideration.

An additional analysis using propensity score matching was also performed. The methods used, as well as results, are described in the supplementary material section.

\section{RESULTS}

Beyond the first 5 years post-implant, which all patients included in the present analysis completed, the mean additional follow-up amongst survivors was 30 months (interquartile range 10-42 months). Table 1 depicts the baseline characteristics of the study patients at the time of CRT implantation or upgrade. As expected, patients receiving CRT-D were significantly younger, more often men and had less advanced heart failure and comorbidity. Upgrade to CRT was less common (as opposed to de novo implantation) compared to CRT-P patients, with greater proportion of ischaemic cardiomyopathy in the CRT-D group. During the time period described in this analysis, only five CRT-P patients (out of 534) were upgraded to CRT-D.

A total of 473 deaths occurred after the first 5 years post-implant, corresponding to unadjusted mortality rates of 94.7 and 139 per 1,000 patient-years for CRT-D and CRT-P patients, respectively. The annual age-standardized mortality rates of our study group were lower than those of the original cohort from which our patients were retrieved -63.4 deaths per 1000 patient-years (95\% CI 57.2-69.5) in the former vs. 85.4 deaths per 1000 patientyears $(95 \%$ CI 80.7-90.2) in the latter. 
When considering the cause-of-death analysis (table 2), twenty-nine patients in total (1.6\%) died of SCD - 15 (1.2\%) with CRT-D and 14 (2.6\%) with CRT-P. This corresponded to $6.1 \%$ of all deaths in both device groups and an annual SCD rate of 7 per 1,000 patientyears (5.8 in CRT-D patients and 8.5 in CRT-P patients). Death due to progressive heart failure represented the principal cause of death in both groups, corresponding to $52.6 \%$ and $42.8 \%$ of known causes in the CRT-D and CRT-P groups, respectively. Approximately one third of deaths was due to a non-cardiovascular cause $-33.1 \%$ of CRT-D and $33.3 \%$ of CRT$\mathrm{P}$ patients. The risk of SCD in each device group in the propensity score matched sample, as well as the percentage of deaths due to SCD, were very similar to those seen in the main analysis (supplementary material).

Among the 250 secondary prevention CRT-D patients, only 2 late SCD were reported, while heart failure death was by far the most frequent (54.1\% of known causes of death).

On multivariate analysis with adjustment on the propensity score, age $(\mathrm{HR}=1.06$, 95\%CI 1.04-1.08, $\mathrm{p}<0.001)$, CRT response $(\mathrm{HR}=0.72,95 \% \mathrm{CI} 0.55-0.95, \mathrm{p}=0.021)$, history of cancer $(\mathrm{HR}=1.70,95 \% \mathrm{CI} 1.19-2.44, \mathrm{p}=0.005), \mathrm{COPD}(\mathrm{HR}=1.68,95 \% \mathrm{CI} 1.20-2.36$, $\mathrm{p}=0.003)$, Diabetes Mellitus $(\mathrm{HR}=1.29,95 \% \mathrm{CI} 1.03-1.61, \mathrm{p}=0.030)$ and, marginally, a lower LV ejection fraction $(\mathrm{HR}=0.98,95 \% \mathrm{CI} 0.97-1.0, \mathrm{p}=0.08)$ were associated with overall mortality, whereas the type of device was not (HR for CRT-D 0.88, 95\%CI 0.70-1.09, $\mathrm{p}=0.24$ ) [figure 1]. There was no significant device-by sex or aetiology interaction. Results obtained after propensity score matching were very similar (supplementary material). Conversely, only LV ejection fraction ( $\mathrm{sHR}=0.93,95 \% \mathrm{CI} 0.88-0.97,0.038)$ associated with late SCD when adjusted on the propensity score and the remaining predictors of SCD in univariate analysis.

For these patients who survived the first 5 years post-implantation, the incidence of any ICD therapy in their first 5 years of follow-up was significantly higher than that reported 
during the time period described in the present analysis ( $25.5 \%$ vs. $11.3 \%$, respectively). The occurrence of "early" ICD therapies was not a predictor of late overall mortality or SCD.

\section{DISCUSSION}

To the best of our knowledge, this represents the first description of very long-term outcomes of CRT recipients who survived the first few years post-implant. Our findings suggest that progressive heart failure death still represents the most frequent cause of death in these patients. By contrast, SCD occurred in less than one per cent of patients every year and represented a very low proportion of late mortality irrespective of the presence of a defibrillator.

Over the last few years, CRT studies with cause-of-death analyses have provided additional insight on the issue of competing risks for mortality. In the CeRtiTude cohort study, the difference in mortality between CRT-D and CRT-P patients was mostly accounted for by an increase in the risk of non-SCD(8). Our study followed a similar rationale and methodology as seen in the landmark CeRtiTuDe study, providing a longer-term assessment of causes of death among patients achieving long survival times following CRT implantation. Our results share some similarities with those seen in CeRtiTuDe. On the one hand, overall unadjusted mortality was significantly higher in the CRT-P group compared with CRT-D, with the different causes of death occurring more frequently in CRT-P patients. This was an expected finding, as CRT-P patients are typically older and tend to have more advanced heart failure and comorbidity. On the other hand, the excess mortality among CRT-P recipients was eventually related to SCD in an almost identical, and very small, proportion of patients. In the Cardiac Resynchronization-Heart Failure (CARE-HF) trial, the $2.5 \%$ annual risk of SCD in the CRT-P group was higher than that reported in our study. The differences may be partly due to the different timings of patient enrolment (2001-03 in CARE-HF vs. 2002-2013 
in the present study), the higher mean patient age in our CRT-P population, with a subsequent increase in the rate of competing non-sudden death, and the fact that our cohort of patients who survived the first 5 years post-implant may represent a healthier lower-risk sub-group of patients.

The low absolute risk of SCD among CRT patients has been recently suggested by large observational studies(5,7). Certainly, responders to CRT are at significantly lower risk of ventricular arrhythmias(21-25), particularly if their LV function normalises after CRT implantation, and CRT alone has been shown to reduce the risk of $\operatorname{SCD}(1)$. Furthermore, the risk of SCD among heart failure patients in general has been progressively decreasing over the last few decades(9). Even if SCD in the CRT context may be more frequent in certain subgroups such as men and those with ischaemic cardiomyopathy $(5,7)$, this cause of death is strikingly less common than death due to heart failure or a non-cardiovascular cause. Our study showed that heart failure and non-cardiovascular death represent the majority of deaths among CRT patients in the very long-term.

In the present study, there was no device-by-sex or device-by-aetiology interaction with regards to mortality benefit, although these interactions have been recently proposed $(5,7,26)$. There are several plausible explanations for this. Firstly, we focused on a selected "healthier" cohort of CRT patients who survived the first 5 years of follow-up. The age-standardized mortality rate of our study group was lower than that calculated for the original cohort who received CRT, which may suggest that patients surviving the first 5 years post-implant have a more benign prognosis, although this could also be the result of continuous improvements in medical therapy. Secondly, it is possible that the benefit of the ICD in the CRT context is most prominent in the first few years post-implantation. In fact, survival curves for CRT-D and CRT-P converged after only 9 months of follow-up in the COMPANION trial. It has been suggested that the lifespan gain from CRT rises nonlinearly 
with time, with higher-risk patients exhibiting more gain early on, while lower-risk patients benefit the most later on(27). Finally, our cohort had completed 5 years of follow-up postCRT implant at the time of enrolment for this study, and the increasing patient age results in a higher percentage of deaths due to competing risk of non-SCD.

Like CeRtiTuDe, our study was not primarily intended as a direct comparison of outcomes between CRT-D and CRT-P patients, as it does not address the question of whether CRT-P would have performed just as well in the group of patients with CRT-D. Some subgroups of patients receiving CRT may have a lower mortality with an additional defibrillator, although definite data is still lacking(28). However, our main goal was to assess the risk of very-late all-cause mortality and SCD in real-world patients who survived the initial 5 years post-CRT implantation. In these patients, the risk of late SCD is very low even in the absence of the defibrillator, and our results, in concert with those of recent studies $(5,7)$, add to the idea that the main benefit of the defibrillator may be seen early after implantation. The higher incidence of ICD therapies in the first 5 years post-CRT implantation compared with those occurred after that time period, as seen in our study, may support this theory, although this may also be the result of less aggressive ICD programming and global improvement in heart failure pharmacological treatments. The development of new DF4 adaptors to allow downgrade to CRT-P at the time of elective generator replacement without the need for an additional lead could be potentially advantageous for elderly primary prevention CRT-D patients who are thought to be at relatively higher risk of non-SCD, particularly given the recent findings of greater risk of device-related complications among CRT-D patients(29). Nevertheless, given that SCD remains a possible, albeit uncommon cause of death in the very long-term, even in a cohort of lower-risk CRT patients who survived the first 5 years of follow-up, a decision to downgrade a CRT-D device to CRT-P should be taken cautiously and after thorough discussion with the patient. 
The main strengths of this study include its multi-centric nature and the very large size of the cohort. However, some limitations should be acknowledged. First, as a nonrandomized study, there was some residual selection bias between device groups even after propensity score adjustment. However, this study was not designed to directly compare the outcomes of CRT-D and CRT-P patients, rather to assess their late causes of death. Second, despite the fact that methods for collecting cause-of-death data were robust, the mechanism of death may be occasionally difficult to determine with certainty. Access to device electrograms could have facilitated the process, but this data was not consistently available. It is possible that some cases of SCD may have been misclassified, but patients dying of unidentified cause were not comparatively more frequent in either device group. Third, baseline characteristics were collected at the time of device implantation. Updated values at 5 years of follow-up were not available for a significant percentage of patients and some parameters (including LV ejection fraction). However, clinical response to CRT was seen in an almost identical percentage of CRT-D and CRT-P patients, suggesting (but not excluding) that an echocardiographic response was not comparatively more frequent in either group.

\section{CONCLUSIONS}

Progressive heart failure death still represents the most frequent cause of death in patients surviving the first five years after CRT implant. By contrast, SCD represents a very low proportion of late mortality irrespective of the presence of a defibrillator. 


\section{ACKNOWLEDGEMENTS}

We would like to thank Dr. Jonatan Jacobsson MD, from the Department of Cardiology of

Lund University, Lund, Sweden, for his valuable contribution to data collection. 


\section{REFERENCES}

1. Cleland JGF, Daubert J-C, Erdmann E, Freemantle N, Gras D, Kappenberger L, Tavazzi L. Longer-term effects of cardiac resynchronization therapy on mortality in heart failure [the CArdiac REsynchronization-Heart Failure (CARE-HF) trial extension phase]. Eur Heart J 2006;27:1928-1932.

2. Cleland JGF, Freemantle N, Erdmann E, Gras D, Kappenberger L, Tavazzi L, Daubert J-C. Long-term mortality with cardiac resynchronization therapy in the Cardiac Resynchronization-Heart Failure (CARE-HF) trial. Eur J Heart Fail 2012;14:628-634.

3. Ghani A, Delnoy PPHM, Adiyaman A, Ottervanger JP, Ramdat Misier AR, Smit JJJ, Elvan A. Predictors and long-term outcome of super-responders to cardiac resynchronization therapy. Clin Cardiol 2017;40:292-299.

4. Barra S, Providência R, Duehmke R, Boveda S, Begley D, Grace A, Narayanan K, Tang A, Marijon E, Agarwal S. Cause-of-death analysis in patients with cardiac resynchronization therapy with or without a defibrillator: A systematic review and proportional meta-analysis. Europace. 2018;20(3):481-491.

5. Barra S, Providência R, Duehmke R, Boveda S, Marijon E, Reitan C, Borgquist R, Klug D, Defaye P, Sadoul N, Deharo J-C, Sadien I, Patel K, Looi K-L, Begley D, Chow AW, Heuzey J-Y Le, Agarwal S. Sex-specific outcomes with addition of defibrillation to resynchronisation therapy in patients with heart failure.

Heart. 2017;103(10):753-760.

6. Køber L, Thune JJ, Nielsen JC, Haarbo J, Videbæk L, Korup E, Jensen G, Hildebrandt P, Steffensen FH, Bruun NE, Eiskjær H, Brandes A, Thøgersen AM, Gustafsson F, Egstrup K, Videbæk R, Hassager C, Svendsen JH, Høfsten DE, Torp-Pedersen C, Pehrson S. Defibrillator Implantation in Patients with Nonischemic Systolic Heart Failure. N Engl J Med. 2016;375(13):1221-30.

7. Barra S, Boveda S, Providência R, Sadoul N, Duehmke R, Reitan C, Borgquist R, Narayanan K, Hidden-Lucet F, Klug D, Defaye P, Gras D, Anselme F, Leclercq C, Hermida J-S, Deharo J-C, Looi K-L, Chow AW, Virdee M, Fynn S, Heuzey J-Y Le, Marijon E, Agarwal S. Adding Defibrillation Therapy to Cardiac Resynchronization on the Basis of the Myocardial Substrate. J Am Coll Cardiol. 2017;69(13):1669-1678.

8. Marijon E, Leclercq C, Narayanan K, Boveda S, Klug D, Lacaze-Gadonneix J, Defaye P, Jacob S, Piot O, Deharo J-C, Perier M-C, Mulak G, Hermida J-S, Milliez P, Gras D, Cesari O, Hidden-Lucet F, Anselme F, Chevalier P, Maury P, Sadoul N, Bordachar P, Cazeau S, Chauvin M, Empana J-P, Jouven X, Daubert J-C, Heuzey J-Y Le. Causesof-death analysis of patients with cardiac resynchronization therapy: an analysis of the CeRtiTuDe cohort study. Eur Heart J. 2015;36(41):2767-76.

9. Shen L, Jhund PS, Petrie MC, Claggett BL, Barlera S, Cleland JGF, Dargie HJ, Granger CB, Kjekshus J, Køber L, Latini R, Maggioni AP, Packer M, Pitt B, Solomon SD, Swedberg K, Tavazzi L, Wikstrand J, Zannad F, Zile MR, McMurray JJV. Declining Risk of Sudden Death in Heart Failure. N Engl J Med. 2017;377(1):41-51. 
10. Goldenberg I, Kutyifa V, Klein HU, Cannom DS, Brown MW, Dan A, Daubert JP, Estes NAM, Foster E, Greenberg H, Kautzner J, Klempfner R, Kuniss M, Merkely B, Pfeffer MA, Quesada A, Viskin S, McNitt S, Polonsky B, Ghanem A, Solomon SD, Wilber D, Zareba W, Moss AJ. Survival with Cardiac-Resynchronization Therapy in Mild Heart Failure. N Engl J Med 2014;370:1694-1701.

11. Barra S, Looi K-L, Gajendragadkar PR, Khan FZ, Virdee M, Agarwal S. Applicability of a risk score for prediction of the long-term benefit of the implantable cardioverter defibrillator in patients receiving cardiac resynchronization therapy.

Europace. 2016;18(8):1187-93.

12. Providência R, Marijon E, Lambiase PD, Bouzeman A, Defaye P, Klug D, Amet D, Perier M, Gras D, Algalarrondo V, Deharo J, Leclercq C, Fauchier L, Babuty D, Bordachar P, Sadoul N, Piot O, Boveda S, Investigators the D, Providencia R, Beganton F, Perier M. Primary Prevention Implantable Cardioverter Defibrillator (ICD) Therapy in Women - Data From a Multicenter French Registry. J Am Heart Assoc. 2016;5(2).

13. Reitan C, Chaudhry U, Bakos Z, Brandt J, Wang L, Platonov PG, Borgquist R. LongTerm Results of Cardiac Resynchronization Therapy: A Comparison between CRTPacemakers versus Primary Prophylactic CRT-Defibrillators. Pacing Clin Electrophysiol. 2015;38(6):758-67.

14. Roubicek T, Wichterle D, Kucera P, Nedbal P, Kupec J, Sedlakova J, Cerny J, Stros J, Kautzner J, Polasek R. Left Ventricular Lead Electrical Delay Is a Predictor of Mortality in Patients With Cardiac Resynchronization Therapy. Circ Arrhythm Electrophysiol; 2015;8:1113-1121.

15. Ioannou A, Papageorgiou N, Barber H, Falconer D, Barra S, Babu G, Ahsan S, Rowland E, Hunter R, Lowe M, Schilling R, Lambiase P, Chow A, Providencia R. Impact of an Age-Adjusted Co-morbidity Index on Survival of Patients With Heart Failure Implanted With Cardiac Resynchronization Therapy Devices. Am J Cardiol. 2017;120(7):1158-1165.

16. Brignole M, Auricchio A, Baron-Esquivias G, Bordachar P, Boriani G, Breithardt OA, Cleland J, Deharo JC, Delgado V, Elliott PM, Gorenek B, Israel CW, Leclercq C, Linde C, Mont L, Padeletti L, Sutton R, Vardas PE; ESC Committee for Practice Guidelines. 2013 ESC guidelines on cardiac pacing and cardiac resynchronization therapy: the task force on cardiac pacing and resynchronization therapy of the European Society of Cardiology (ESC). Eur Heart J. 2013;34:2281-32.

17. Landolina M, Curnis A, Morani G, Vado A, Ammendola E, D'onofrio A, Stabile G, Crosato M, Petracci B, Ceriotti C, Bontempi L, Morosato M, Ballari GP, Gasparini M. Longevity of implantable cardioverter-defibrillators for cardiac resynchronization therapy in current clinical practice: an analysis according to influencing factors, device generation, and manufacturer. Europace 2015;17:1251-1258.

18. Alam MB, Munir MB, Rattan R, Adelstein E, Jain S, Saba S. Battery longevity from cardiac resynchronization therapy defibrillators: differences between manufacturers 
and discrepancies with published product performance reports. Europace. 2017 $1 ; 19(3): 421-424$.

19. European Standard Population (ESP). https://www.causesofdeath.org/docs/standard.pdf (25 November 2018)

20. Austin PC. Propensity-score matching in the cardiovascular surgery literature from 2004 to 2006: a systematic review and suggestions for improvement. J Thorac Cardiovasc Surg 2007;134:1128-1135.

21. García-Lunar I, Castro-Urda V, Toquero-Ramos J, Mingo-Santos S, MoñivasPalomero V, Daniela Mitroi C, Sánchez-García M, Pérez-Pereira E, Delgado HE, Fernández-Lozano I. Ventricular arrhythmias in super-responders to cardiac resynchronization therapy. Rev Esp Cardiol 2014;67:883-889.

22. Hsu JC, Solomon SD, Bourgoun M, McNitt S, Goldenberg I, Klein H, Moss AJ, Foster E, MADIT-CRT Executive Committee. Predictors of super-response to cardiac resynchronization therapy and associated improvement in clinical outcome: the MADIT-CRT study. J Am Coll Cardiol 2012;59:2366-2373.

23. Thijssen J, Borleffs CJW, Delgado V, Rees JB van, Mooyaart EAQ, Bommel RJ van, Erven L van, Boersma E, Bax JJ, Schalij MJ. Implantable cardioverter-defibrillator patients who are upgraded and respond to cardiac resynchronization therapy have less ventricular arrhythmias compared with nonresponders. J Am Coll Cardiol 2011;58:2282-2289.

24. Ruwald MH, Solomon SD, Foster E, Kutyifa V, Ruwald A-C, Sherazi S, McNitt S, Jons C, Moss AJ, Zareba W. Left ventricular ejection fraction normalization in cardiac resynchronization therapy and risk of ventricular arrhythmias and clinical outcomes: results from the Multicenter Automatic Defibrillator Implantation Trial With Cardiac Resynchronization Therapy. Circulation 2014;130:2278-2286.

25. Schaer BA, Osswald S, Valentino M Di, Soliman OI, Sticherling C, Cate FJ ten, Jordaens L, Theuns DA. Close connection between improvement in left ventricular function by cardiac resynchronization therapy and the incidence of arrhythmias in cardiac resynchronization therapy-defibrillator patients. Eur J Heart Fail 2010;12:1325-1332.

26. Leyva F, Zegard A, Umar F, Taylor RJ, Acquaye E, Gubran C, Chalil S, Patel K, Panting J, Marshall H, Qiu T. Long-term clinical outcomes of cardiac resynchronization therapy with or without defibrillation: impact of the aetiology of cardiomyopathy. Europace. 2018. doi: 10.1093/europace/eux357.

27. Finegold JA, Raphael CE, Levy WC, Whinnett Z, Francis DP. Quantification of survival gain from cardiac resynchronization therapy: nonlinear growth with time, and greater gain in low-risk patients, make raw trial data an underestimate of real-world behavior. J Am Coll Cardiol; 2013;62:2406-2413. 
28. Woods B, Hawkins N, Mealing S, Sutton A, Abraham WT, Beshai JF, Klein H, Sculpher M, Plummer CJ, Cowie MR. Individual patient data network meta-analysis of mortality effects of implantable cardiac devices. Heart. 2015;101(22):1800-06.

29. Barra S, Providência R, Boveda S, Duehmke R, Narayanan K, Chow AW, Piot O, Klug D, Defaye P, Gras D, Deharo J-C, Milliez P, Costa A Da, Mondoly P, GonzalezPanizo J, Leclercq C, Heck P, Virdee M, Sadoul N, Heuzey J-Y Le, Marijon E. Device complications with addition of defibrillation to cardiac resynchronisation therapy for primary prevention. Heart. 2018. pii: heartjnl-2017-312546. doi: 10.1136/heartjnl2017-312546. 


\section{FIGURE LEGENDS}

Figure 1: Cumulative late adjusted survival in cardiac resynchronization therapy defibrillator (CRT-D) and pacemaker (CRT-P) patients 
Table 1 - Baseline characteristics at the time of CRT implantation or upgrade

\begin{tabular}{|c|c|c|c|}
\hline$\underline{\text { Variable }}$ & CRT-D (n=1241) & CRT-P (n=534) & p-value \\
\hline Age (years)* & $63.8 \pm 10.4 *$ & $69.8 \pm 10.2 *$ & $<0.001$ \\
\hline Male sex & $80.4 \%(998)$ & $69.7 \%(372)$ & $<0.001$ \\
\hline Left ventricular ejection fraction $(\%)$ & $25.5 \pm 6.3$ & $26.8 \pm 7.6$ & $<0.001$ \\
\hline NYHA class $\geq 3$ & $68.3 \%(847)$ & $82 \%(438)$ & $<0.001$ \\
\hline QRS duration $<120 \mathrm{~ms}$ & $7.7 \%(95)$ & $3.4 \%(18)$ & \\
\hline $120-150 \mathrm{~ms}$ & $33.8 \%(420)$ & $24.9 \%(133)$ & $<0.001$ \\
\hline$>150 \mathrm{~ms}$ & $58.6 \%(727)$ & $71.7 \%(383)$ & \\
\hline Ischaemic aetiology & $52.5 \%(652)$ & $47.8 \%(255)$ & 0.072 \\
\hline Upgrade to CRT & $14.2 \%(176)$ & $23.6 \%(126)$ & $<0.001$ \\
\hline History of atrial fibrillation & $47.1 \%(584)$ & $42.7 \%(228)$ & 0.091 \\
\hline History of stroke or transient ischaemic attack & $7.5 \%(93)$ & $11.6 \%(62)$ & 0.004 \\
\hline History of chronic obstructive pulmonary disease & $11 \%(137)$ & $9.9 \%(53)$ & 0.4 \\
\hline History of Diabetes Mellitus & $26.7 \%(331)$ & $28.1 \%(150)$ & 0.3 \\
\hline History of cancer & $8.9 \%(111)$ & $9.9 \%(53)$ & 0.5 \\
\hline Glomerular filtration rate $\geq 60 \mathrm{ml} / \mathrm{min}$ & $56.7 \%(704)$ & $43.1 \%(230)$ & \\
\hline $30-59 \mathrm{ml} / \mathrm{min}$ & $38.2 \%(474)$ & $52.2 \%(279)$ & $<0.001$ \\
\hline$<30 \mathrm{ml} / \mathrm{min}$ & $5.1 \%(63)$ & $4.7 \%(25)$ & \\
\hline On beta-blockers & $79.1 \%(982)$ & $74.2 \%(396)$ & 0.06 \\
\hline On ACEI/ARA-II & $83.5 \%(1036)$ & $91.4 \%(488)$ & 0.005 \\
\hline On aldosterone antagonists & $32.4 \%(402)$ & $43.3 \%(231)$ & $<0.001$ \\
\hline Secondary prevention & $20.1 \%(250)$ & - & - \\
\hline Clinical responder to CRT during follow-up** & $73.8 \%(717)^{* *}$ & $71.4 \%(314)^{* *}$ & 0.3 \\
\hline Mean follow-up in surviving patients (months) & $85.5 \pm 21.6$ & $102.9 \pm 33.6$ & $<0.001$ \\
\hline
\end{tabular}

ACEI- Angiotensin converting enzyme inhibitor; ARA-II- Type 2 angiotensin receptor antagonist; CRT-

Cardiac resynchronization therapy; NYHA- New York Heart Association

* Mean age of the cohort for the present study was 5 years higher

** Data available for 971 CRT-D and 441 CRT-P patients 
Table 2 - Incidence rate of specific causes of death among CRT-D and CRT-P patients (events per 1000 patient-years), with corresponding unadjusted and adjusted Hazard Ratios

\begin{tabular}{|c|c|c|c|c|}
\hline & $\begin{array}{r}\text { CRT-D } \\
(n=1241)\end{array}$ & $\begin{array}{l}\text { CRT-P } \\
(n=534)\end{array}$ & $\begin{array}{c}\text { Unadjusted HR } \\
(95 \% \mathrm{CI})\end{array}$ & $\begin{array}{c}\text { Adjusted HR } \\
(95 \% \mathrm{CI})\end{array}$ \\
\hline Total mortality & 94.7 & 139.0 & $0.67(0.56-0.81)$ & $0.99(0.79-1.22)$ \\
\hline SCD & 5.8 & 8.5 & $0.65(0.31-1.37)$ & $1.0(0.45-2.44)$ \\
\hline Heart failure & 40.2 & 52.0 & $0.76(0.57-1.02)$ & $1.1(0.81-1.58)$ \\
\hline Other cardiovascular & 5.1 & 20.5 & $0.25(0.13-0.48)$ & $0.30(0.14-0.63)$ \\
\hline Non-cardiovascular & 25.0 & 40.5 & $0.62(0.43-0.87)$ & $1.0(0.67-1.49)$ \\
\hline Unidentified & $\begin{array}{l}16.9 \% \text { of } \\
\text { deaths, } \\
3.3 \% \text { of } \\
\text { patients }\end{array}$ & $\begin{array}{l}11.3 \% \text { of } \\
\text { deaths, } \\
4.9 \% \text { of } \\
\text { patients }\end{array}$ & $1.0(0.61-1.66)$ & $1.5(0.85-2.82)$ \\
\hline
\end{tabular}

